ISSN 0103-8478

\title{
Citologia do leite de búfalas (Bubalus bubalis) hígidas criadas no Estado de São Paulo, Brasil
}

\author{
Milk citology of healthy buffaloes (Bubalus bubalis) bred \\ in São Paulo state, Brazil
}

\author{
Alice Maria Melville Paiva Della Libera ${ }^{1}$ Wanderley Pereira de Araujo ${ }^{2}$ \\ Sandra Satiko Kitamura ${ }^{3}$ Andrea Mello Franco Rosenfeld ${ }^{4}$ \\ Eduardo Harry Birgel ${ }^{5}$
}

\section{RESUMO}

As avaliações quantitativas e qualitativas das células presentes no leite são empregadas para a compreensão de diversos processos, fisiológicos ou não da glândula mamária. Apesar disso, as citações da literatura são conflitantes quanto às búfalas sadias e, para elucidar essa questão, avaliou-se a celularidade do leite em 108 amostras de quartos mamários de búfalas hígidas em lactação, submetendo-as à contagem de células somáticas (CCS), automática e por microscopia óptica, além de estabelecer-se a predominância celular empregando duas técnicas (Prescott e Breed e citocentrifugação). Os resultados das CCS do leite, por técnicas microscópica e automática foram semelhantes, mas a predominância celular analisada por microscopia diferiu em valores relativos. Foram identificadas mais células mononucleares nas lâminas de suspensão celular citocentrifugada, e mais leucócitos polimorfonucleares na técnica de Prescott e Breed. A lâmina de citocentrifugação permitiu melhor avaliação da morfologia celular sendo identificados $61,1 \%$ de monócitos e macrófagos; $32,9 \%$ de neutrófilos; $5,3 \%$ de linfócitos e 0,7\% de eosinófilos. Os fagócitos mononucleares apresentaram uma acentuada plasticidade de suas estruturas, com variados padrões morfológicos.

Palavras-chave: búfalo, leite, leucócitos, células somáticas

\section{ABSTRACT}

The quantitative and qualitative evaluations of cells present on milk are important for understanding many events, physiologic or not, of the mammary gland. Despite that, citations in the literature are conflicting concerning healthy buffaloes. This study evaluated milk cellularity in 108 samples of healthy buffaloes mammary glands. They were analyzed by somatic cell count automatic and microscopic, and the cellular types in slides of milk smear and also after cytocentrifugation of cellular suspension (differential citology evaluation). Results of milk somatic cells count, by microscopic and automatic techniques, were similar but cellular predominance (from Prescott - Breed or cytocentrifugation) differed in relative values. More mononuclear cells were found in slides of cytocentrifugation of cellular suspension smears and more leucocytes on direct microscopic count technique. The cytocentrifugation smears showed a better evaluation of cellular morphology, identifying $61.1 \%$ of monocytes and macrophages, $32.9 \%$ of neutrophils, $5.3 \%$ of lymphocytes and $0.7 \%$ of eosinophils. Mononuclear phagocytes showed a high plasticity on structure with many morphological patterns.

Key words: buffaloes, milk, leukocytes, somatic cells.

\section{INTRODUÇÃO}

O perfil celular do leite representa importante subsídio na avaliação da saúde da glândula mamária (SCHALM et al., 1971; VIANNI et al., 1990; PAAPE et al., 2000). As informações disponibilizadas quanto aos mecanismos de defesa da glândula mamária de bovinos (LEE et al., 1980; JENSEN \& EBERHART, 1981; SANDGREN et al., 1991; DULIN et al., 1992; ÖSTENSSON, 1993) muitas vezes são adaptadas para bubalinos, sem considerar suas particularidades. Em pesquisas realizadas com bubalinos, SILVA \& SILVA (1994) inferiram serem as búfalas mais resistentes às mamites do que os bovinos, apresentando diferenças quantitativas e qualitativas da celularidade do leite desses dois ruminantes. DHAKAL et al. (1992), ao realizarem a contagem diferencial de células somáticas no início e

\footnotetext{
${ }^{1}$ Médico Veterinário, Doutor, Professor de Clínica Médica do Departamento de Clínica Médica (VCM), Faculdade de Medicina Veterinária e Zootecnia (FMVZ), Universidade de São Paulo (USP), Av. Professor Orlando Marques de Paiva, 87, 05508-000, Cidade Universitária, São Paulo, SP. E-mail: dellalibera@fmvz.usp.br. Autor para correspondência.

${ }^{2}$ Médico Veterinário, Doutor, Professor Associado, Livre Docente, VCM, FMVZ, USP

${ }^{3}$ Médico Veterinário, Doutorando, VCM, FMVZ,USP, Professor de Clínica Médica, UNIP.

${ }^{4}$ Médico Veterinário, Mestrando, VCM, FMVZ, USP.

${ }^{5}$ Médico Veterinário, Doutor, Professor Titular, VCM, FMVZ, USP, Coordenador do Projeto de Auxílio Pesquisa-FAPESP (00/04113-4).
} 
no fim da ordenha de búfalas sadias, descreveram um predomínio de células epiteliais sobre polimorfonucleares neutrófilos, mononucleares linfócitos e monócitos. Nos casos de amostras de leite provenientes de búfalas acometidas por mamite com processos inflamatórios inespecíficos (CCS > 500.000 células/ml e cultura bacteriológica negativa), DHAKAL et al. (1992) referiram predomínio de polimorfonucleares neutrófilos, seguidos de linfócitos, células epiteliais e monócitos. Nas infecções latentes (CCS < 500.000 células/ml e exame microbiológico positivo), os autores também descreveram predomínio de neutrófilos, embora fosse menor do que nas amostras de búfalas acometidas por mamites. A exemplo do que já é descrito para bovinos, os autores sugeriram que uma contagem de células somáticas menor que 500.000 células/ml não indicaria necessariamente leite obtido de glândula mamária livre de mamite.

No Sri Lanka, no leite de búfalas de diversas raças, SILVA \& SILVA (1994) relataram que nas amostras consideradas normais (CMT negativo e valores médios de $\mathrm{pH}$ de 6,58) a contagem total de células somáticas variou de 50.000 a 375.000 células/ $\mathrm{ml}$, sendo predominantes os leucócitos do tipo polimorfonuclear neutrófilo com maior número relativo $(56 \%)$ do que o obtido no leite de vacas, seguidos, dos linfócitos (28\%), macrófagos (8\%), células epiteliais $(5 \%)$ e os polimorfonucleares eosinófilos (1\%).

Em amostras de leite de búfalas provenientes de glândula mamária não infectada, independentemente da fase de lactação, GUARINO et al. (1994) referiram predomínio de macrófagos em três principais formas: células espumosas, em forma de anel e como monócitos comuns.

Dada a exigüidade e diversidade de informações quanto à celularidade do leite de búfalas hígidas e a importância que essas informações representam para a compreensão dos mecanismos basais de defesa celular da mama, o objetivo do presente estudo foi avaliar, quantitativa e qualitativamente, a celularidade de amostras de leite de quartos mamários de búfalas hígidas criadas no Estado de São Paulo, empregando diferentes técnicas,

\section{MATERIAL E MÉTODOS}

Foram selecionadas 28 búfalas da raça murrah, sem alterações ao exame físico dos quartos mamários, CMT e exame microbiológico do leite negativos. Destes animais, foram colhidas 108 amostras de leite, subdivididas em quatro alíquotas cada. A primeira alíquota de leite $(n=108)$ foi colhida assepticamente, semeada em placa de Petri contendo ágar-sangue de carneiro $(5 \%)$ e incubada a $37^{\circ} \mathrm{C}$ por 24 e 48 horas, para confirmar a inclusão exclusiva de amostras negativas. A segunda alíquota $(n=108)$ foi colhida com conservante bronopol e destinouse à contagem de células somáticas em contador eletrônico infravermelho A terceira alíquota $(n=70)$ foi submetida à contagem das células por microscopia óptica direta (PRESCOTT \& BREED, 1910) e diferenciação em mononucleares e polimorfonucleares. A quarta alíquota $(n=108)$ possuía 500ml de leite e foi colhida em frasco contendo a mesma quantidade de PBS (1:1) e destinava-se à recuperação de células para a contagem diferencial pela técnica da citocentrifugação. No laboratório, essa mistura foi dividida em vários frascos tipo Falcon de $50 \mathrm{ml}$ cada e submetida à primeira centrifugação $(450 \mathrm{~g}$ por 20 minutos, à $4^{\circ} \mathrm{C}$ ). O sobrenadante mais viscoso, na fase de separação, sobre a fração líquida (tampão de gordura), foi retirado e, após desprezar a fração sobrenadante invertendo-se os frascos uma única vez, mantiveram-se os mesmos invertidos para limpar os lados do frasco com papel macio e absorvente. Os botões de células precipitados foram desprendidos pela aspersão de PBS, sendo os mesmos concentrados em um único frasco Falcon completando-se nesse o volume de $50 \mathrm{ml}$ com PBS refrigerado. A suspensão foi novamente centrifugada, nas condições já mencionadas, o sobrenadante desprezado e o botão de células ressuspendido em $1 \mathrm{ml}$ com meio

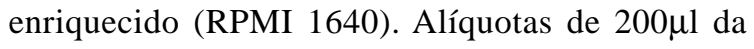
suspensão celular foram submetidas a citocentrifugação a uma força centrífuga real (FCR) de $28 \mathrm{~g}$ durante seis minutos. A partir do sedimento, confeccionaram-se lâminas em duplicatas, que foram coradas, pelo método descrito por ROSENFELD (1947) para então serem contadas e diferenciadas 400 células em microscopia de campo claro (1000x). Os sobrenadantes foram avaliados por amostragem $(\mathrm{n}=50)$ quanto à perda de células durante o preparo da suspensão celular.

Os resultados obtidos foram submetidos ao teste de normalidade de Kolmogorov-Smirnov. Os valores relativos de mononucleares e polimorfonucleares obtidos pela técnica de microscopia óptica direta, e por citocentrifugação, foram submetidos à análise de variância e as diferenças avaliadas pelo teste de Duncan (SAMPAIO, 1998), por apresentarem distribuição paramétrica. As contagens de células somáticas apresentaram distribuição não-paramétrica sendo as comparações pareadas avaliadas pelo método de 
Wilcoxon e, complementarmente foram calculadas as médias e respectivos valores percentuais dos tipos celulares identificados na citocentrifugação.

\section{RESULTADOS}

As medianas das CCS do leite de búfalas determinadas automática e microscopicamente foram semelhantes $(p>0,3)$ e respectivamente, 13.000 e 18.000 células/ml de leite.

Qualitativamente houve diferença no estabelecimento do tipo celular predominante nas amostras citocentrifugadas ( $\mathrm{p}<0,0001$; tabela 1 ) onde se observou uma porcentagem média de células mononucleares significativamente maior $(\mathrm{p}<0,0001)$ do que a obtida por microscopia óptica direta na qual foram encontrados valores semelhantes de mono e polimorfonucleares $(p>0,5)$. Apesar dessas diferenças, os valores médios relativos de polimorfonucleares verificados nesta última, foram significativamente maiores do que na amostra citocentrifugada $(\mathrm{p}<0,0001)$.

Na tabela 2, estão apresentados os valores médios da contagem diferencial em amostra citocentrifugada. Destaque-se que os eosinófilos não apresentaram distribuição normal e, por isso, o resultado foi expresso em mediana e dois desvios padrão. Os tipos celulares identificados estão apresentados na figura 1 .

Da amostragem dos 50 sobrenadantes citocentrifugados para verificar a perda de células durante o processamento, não foram recuperadas células.

\section{DISCUSSÃO}

A análise dos resultados das contagens de células somáticas, demonstrou um pequeno valor de células somáticas (13.000 e 18.000 células/ml), em ambas as técnicas empregadas. Esses resultados foram menores do que os descritos pela grande maioria dos

Tabela 1 - Valores relativos (\%) médios e respectivos desvios padrão dos tipos de células somáticas do leite de búfalas sadias, segundo a técnica de contagem.

\begin{tabular}{lll}
\hline Tipos celulares & \multicolumn{2}{c}{ Técnica de contagem celular } \\
\hline & Microscopia direta & Citocentrifugação \\
Mononuclear $(\%)$ & $51,6^{\mathrm{a}} \pm 27,0$ & $66,4^{\mathrm{a}} \pm 19,0$ \\
Polimorfonuclear $(\%)$ & $48,4^{\mathrm{a}} \pm 27,0$ & $33,6^{\mathrm{b}} \pm 19,0$ \\
Significância & $\mathrm{p}>0,5$ & $\mathrm{p}<0,0001$ \\
\hline
\end{tabular}

Letras distintas na mesma coluna indicam diferenças entre si. autores em leite de bovinos não acometidos de mamite (SCHALM, 1971) e mesmo em bubalinos (SILVA \& SILVA, 1994).

A diferença verificada entre o número de células somáticas do leite de búfalas obtidas por SILVA \& SILVA (1994) e os determinados nesse estudo, pode ter sido causada pela diversidade de técnicas de contagem celular utilizadas, pois os referidos pesquisadores usaram o hemocitômetro específico para contagem de leucócitos sangüíneos. Além disso, na presente pesquisa utilizou-se, como critérios para a seleção dos animais o exame físico da glândula mamária, e os resultados negativos do CMT e exame bacteriológico, enquanto SILVA \& SILVA (1994) usaram apenas o resultado do CMT e do pH. As duas técnicas utilizadas apresentaram resultados semelhantes, validando a contagem automática para bubalinos e conseqüentemente favorecendo a avaliação de um maior número de amostras em menor tempo.

Justifica-se a avaliação da composição celular no leite de búfalas sadias por refletir a atividade celular predominante no momento da colheita, população essa que garantiria a defesa basal da mama e mobilizaria os primeiros recursos no caso de uma agressão. A contagem celular por microscopia óptica direta revelou valores semelhantes de células polimorfonucleares e mononucleares no leite de glândulas mamárias hígidas, não permitindo uma adequada especificação celular. O número de células do leite foi considerado pequeno e, muitas vezes, o volume de leite necessário à técnica poderia não ser representativo da quantidade real, uma vez que cada célula equivaleria a aproximadamente 4000 células/ $\mathrm{ml}$ após a conversão empregando o fator do microscópio.

No entanto, avaliando-se o sedimento ressuspendido e citocentrifugado, foi evidenciado maior número de células mononucleares do que na contagem microscópica direta. Considerando-se na diferenciação apenas as células mononucleares e polimorfonucleares praticamente houve predomínio da série de monócito/macrófago entre os mononucleares, pois o número de linfócitos foi muito pequeno. Quanto aos leucócitos polimorfonucleares, foram representados quase que exclusivamente pelos neutrófilos, pois em poucas amostras foram observados alguns eosinófilos, tal como já descrito para bovinos por SCHALM et al. (1971). O número de linfócitos observados neste estudo foi maior do que os padrões relativos desta célula estabelecidos por DHAKAL et al. (1992) e SILVA \& SILVA (1994). A técnica descrita por PRESCOTT \& BREED (1910), 
Tabela 2 - Valores absolutos (cel/ml), porcentagens médios e mediana dos diferentes tipos celulares observados pela técnica da citocentrifugação de 108 amostras de leite de búfalas sadias.

\begin{tabular}{lcccc}
\hline & & \multicolumn{2}{c}{ Tipo celular } \\
\hline & macrófagos/monócitos & Neutrófilos & Linfócitos & Eosinófilos \\
Valores absolutos médios (Desvio padrão) & $244,65( \pm 72,96)$ & $131,51( \pm 76,07)$ & $21,14( \pm 19,28)$ & - \\
Valores relativos médios $(\%)$ & 61,1 & 32,9 & 5,3 & - \\
Mediana & - & - & 0,7 & $-00(0-8)$ \\
\hline
\end{tabular}

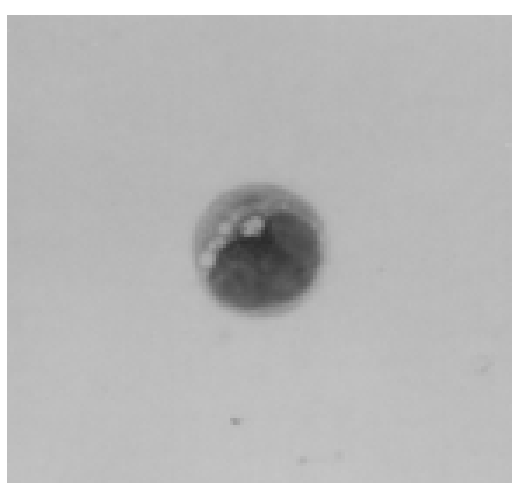

a) Monócito

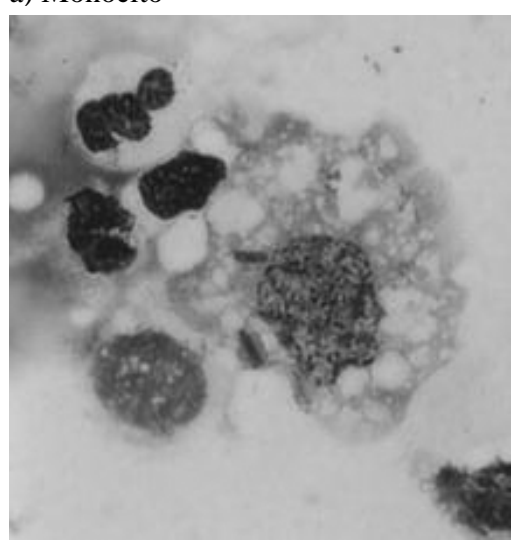

c) Macrófago vacuolizado (seta)

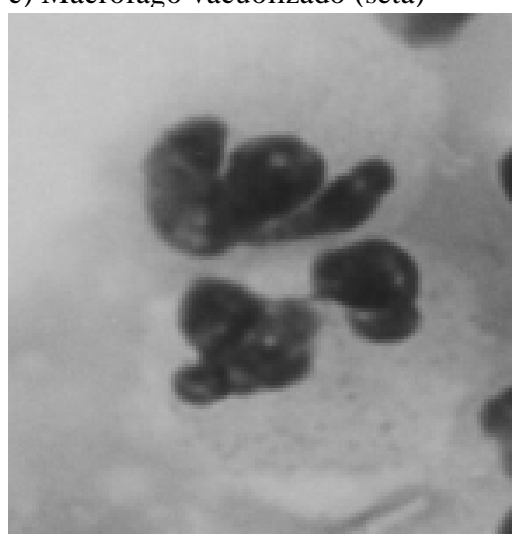

e) Polimorfonucleares - Neutrófilos

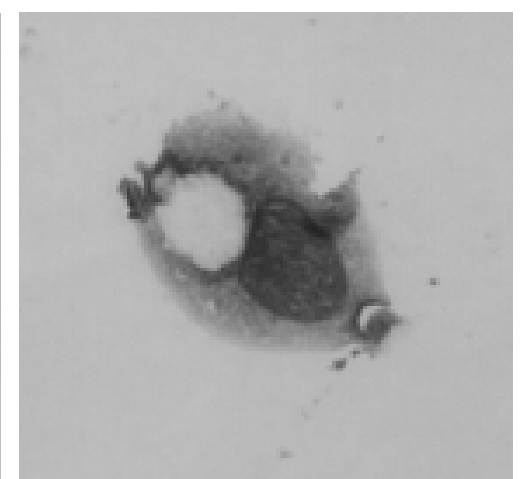

b) Macrófago com vacúolo

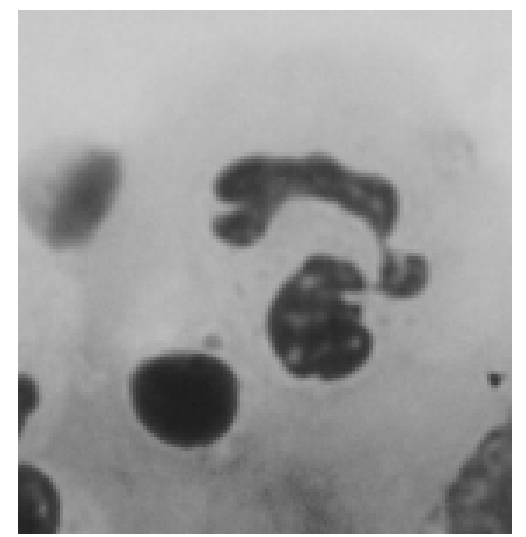

d) Linfócito (seta)

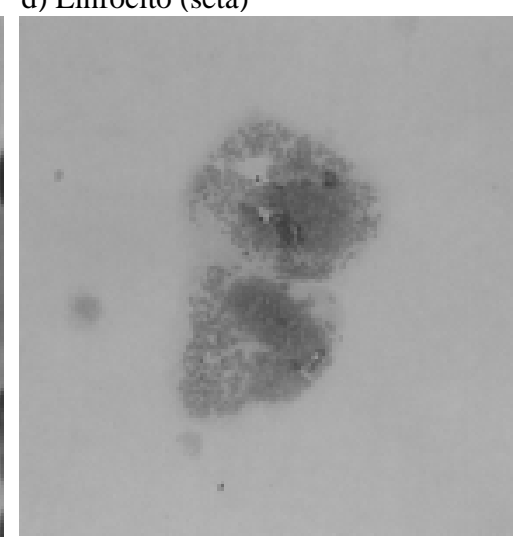

f) Eosinófilos

Figura 1 - Fotomicrografias de células de amostras de búfalas (Bubalus bubalis) hígidas, identificadas morfologicamente empregando microscopia óptica de imersão (1000x).

apesar de adequada para a contagem de células somáticas de leite, apresentou significativas limitações para o exame diferencial, sendo indicada para avaliações qualitativas de esfregaços corados, classificando apenas o tipo de predominância celular em mono ou polimorfonuclear.

SCHALM et al. (1971) referiram que a diversidade dos resultados citados pelos diferentes autores poderia ser atribuída não só às variações resultantes das manifestações da própria glândula mamária, como também, dos procedimentos de contagem. Por tal razão, consideraram que a análise do esfregaço do sedimento celular do leite após a citocentrifugação permitiria melhor avaliação das condições fisiológicas e da atividade celular na glândula mamária, por meio de uma adequada interpretação das características morfo-tinturiais das células mas, deveria ser considerada na interpretação do exame a possibilidade de perda de células durante o processamento da amostra. Segundo os mencionados autores, essas células poderiam ser perdidas não só no sobrenadante centrifugado, como também no tampão de gordura que se concentra como fração menos densa do material, pois ressaltaram que as células somáticas do leite apresentam afinidade pela gordura interferindo assim quantitativamente na avaliação dos esfregaços de leite. Neste estudo, o sobrenadante foi avaliado e não foi 
constatada a perda de células, suposta por SCHALM et al. (1971) e DULIN et al. (1982). Todavia, tal avaliação não foi realizada no tampão de gordura. A diferença encontrada no predomínio celular entre a microscopia óptica direta e a citocentrifugação poderia ser atribuída à perda de células retidas no tampão de gordura do leite, porém a hipótese dos autores supracitados foi desconsiderada, pois caso houvesse, a célula que apresentaria maior afinidade pela gordura, portanto com maior perda na citocentrifugação seria o macrófago, justamente a célula que predominou.

Através da contagem das células somáticas por microscopia óptica direta, foi possível uma razoável identificação celular, concordando com a afirmação de BENITES et al. (2001) que consideraram essa coloração prática e satisfatória em leite bovino, embora preferissem, para a contagem celular, a coloração pela hematoxilina e eosina.

Os valores percentuais das células identificadas após citocentrifugação (Tabela 2) diferiram dos valores obtidos por DHAKAL et al. (1992) que referiram predomínio de células epiteliais seguidos dos linfócitos, neutrófilos e monócitos. Discordantes também foram os resultados obtidos nesta pesquisa daqueles verificados em diversas raças de búfalas do Sri Lanka por SILVA \& SILVA (1994) que evidenciaram predomínio de polimorfonucleares neutrófilos sobre as demais células do leite, inclusive obtendo valor percentual maior do que o observado em vacas. Baseados nos seus resultados SILVA \& SILVA (1994) justificaram maior resistência das búfalas à mamite a maior disponibilidade de polimorfonucleares neutrófilos, no leite desses animais, fato não comprovado nesta investigação pois os valores destas células foram inferiores aos constatados por aqueles autores.

PAAPE et al. (2000), sumarizando informações sobre as células presentes no leite de bovinos, referiram valores percentuais de células da série monócito/macrófago de 35-79\%, semelhantes aos encontrados neste estudo, em leite de búfalas $(61,1 \%)$ todavia, os valores relativos das demais células presentes no leite, como neutrófilos, linfócitos e eosinófilos, descritos por esses autores diferiram dos referidos nesse estudo. Apesar de 32\% das células presentes serem neutrófilos, o mesmo não indicaria um processo inflamatório presente por representar a metade dos monócito/macrófago presentes.

SCHALM et al. (1971) salientaram a diversidade de descrições na diferenciação das células somáticas do leite das vacas, levando vários pesquisadores a classificar diferentemente o mesmo tipo celular. Células que apresentavam morfologia nuclear variada por encontrarem-se em diferentes funções e graus de ativação, além de diferentes características morfo-tintoriais, como observado nas células da série monócito/macrófago, aumentavam a possibilidade de erro nas suas identificações (LEE et al., 1980; JENSEN \& EBERHART, 1981; ÖSTENSSON, 1993). Talvez por tal razão SANDGREN et al. (1991) preferiram englobar numa única categoria celular os macrófagos e as células epiteliais (MEC), destacando porém que os macrófagos eram as células predominantes, afirmação concordante com os resultados obtidos nesta pesquisa. Além disso, segundo LEE et al. (1980) as células epiteliais presentes no leite tanto de bovinos como de bubalinos, representariam um valor percentual mínimo na celularidade.

\section{CONCLUSÕES}

A contagem de células somáticas por microscopia óptica direta e automática apresentaram resultados semelhantes e extremamente diminutos. Quanto à predominância celular, houve diferenças significativas conforme a técnica empregada, encontrando-se pela técnica de contagem por microscopia óptica direta, valores semelhantes de células mononucleares e polimorfonucleares; enquanto pela técnica de citocentrifugação da suspensão celular, verificou-se predomínio de mononucleares, principalmente monócitos e macrófagos, em diferentes fases evolutivas.

\section{REFÊRENCIAS BIBLIOGRÁFICAS}

BENITES, N.R.; MELVILLE, P.A.; COSTA, E.O. Modificação da técnica de contagem de células somáticas de Prescott e Breed utilizando-se a coloração de Hematoxilina e Eosina. NAPGAMA, São Paulo, v.4, n.3, p.6-9, 2001.

DHAKAL, I.P.; KAPUR, M.P.; SHARMA, A. Significance of differential somatic cell counts in milk for the diagnosis of subclinical mastitis in buffaloes using foremilk and strippings milk. Indian Journal of Animal Health, v.31, n.1, p.39-42, 1992.

DULIN, A.M.; PAAPE, M.J.; WEINLAND, B.T. Cytospin centrifuge in differential counts of milk somatic cells. Journal of Dairy Science, n.65, p.1247-1251, 1982.

GUARINO, A. et al. Types of cells present in buffaloes milk. In: WORLD BUFFALO CONGRESS, 4, 1994, Pirssununga, SP. Anais... São Paulo : ABCB, 1994. p.187-189.

JENSEN, D.L.; EBERHART, R.J. Total and differential cell counts in secretions of the nonlactating bovine mammary gland. American Journal Veterinary Research, n.42, p.743-747, 1981.

LEE, C.; WOODING, F. B.; KEMP, P. Identification, properties, and differential counts of cell populations using microscopy of 
dry cows secretions, colostrum and milk from normal cows. Journal of Dairy Research, n.47, p.39-50, 1980.

ÖSTENSSON, K. Trafficing of leukocytes and immunoglobulin isotypes in the bovine udder. Studies of milk, lymph and blood from cows with healthy and mastitic mammary glands. 1993. 67f. Tese (Doctor-Obstetrics and Gynaecology) - University of Agricultural Sciences, Faculty of Veterinary Medicine Swedish University of Agricultural Sciences.

PAAPE, M.J. et al. Immune surveillance of mammary tissue by phagocytic cells. Adv Exp Med Biol, v.480, p.259-277, 2000 .

PRESCOTT, S.C.; BREEED, R.S. The determination of the number of body cells in milk by a direct method. Journal of Infection Disease, n.7, p.632, 1910 .

ROSENFELD, G. Corante pancrômico para hematologia e citologia clínica. Nova combinação dos componentes de May-
Grunwald e do Giemsa num só corante de emprego rápido. Mem Inst Butantan, n.20, p.329-335, 1947.

SAMPAIO, I.B.M. Estatística aplicada à experimentação animal. Belo Horizonte : Universidade Federal de Minas Gerais, 1998. 221p.

SANDGREN, C.H.; NORDLING, K.; BJÖRK, I. Isolation and phagocytic properties of neutrophils and other phagocytes from nonmastitic bovine milk. Journal of Dairy Science, n.74, p.29652975, 1991.

SCHALM, O.W.; CARROL, E.J.; JAIN, N.C. Bovine mastitis. Philadelphia : Lea e Febiger, 1971. 360p.

SILVA, I.D.; SILVA, K.F.S.T. Total and differential cell counts in buffalo (Bubalus bubalis) milk. Buffalo Journal, v.10, n.2, p.133-137, 1994.

VIANNI, M.C.E. et al. Eficiência do California Mastitis Test (CMT) na estimativa do número de células somáticas do leite bubalino. Ciência Veterinária, Jaboticabal, v.4, n.2, p.3-4, 1990. 